\title{
Teaching and Learning Writing Skills through Literature
}

\author{
Karwan Karim Abdalrahman ${ }^{1}$ \\ ${ }^{1}$ English Language Teaching Department, Tishk International University, Erbil, Iraq \\ Email: karwan.karim@tiu.edu.iq
}

DOI: $10.53103 /$ cjlls.v1i2.11

\begin{abstract}
Recently, there is a lot of academic discussion among language and literary scholars regarding utilizing literature in English language classrooms. Some studies were conducted and showed the positive effects of literary texts in second language acquisition. These studies proved that using literature motivates and engages students better than just depending on linguistic textbooks. In fact, they stated that literary genres are the field where language rules can be read in use. This study is a descriptive qualitative analysis that used secondary sources including research articles written between 2015-2021 to explore the findings of the current literature on using literature in teaching and learning writing skills. Therefore, the collected data is analyzed thematically. English language instructors integrate literary genres, including short stories, novels, plays, and poems, into their language courses to enrich both their teaching style and to bring about a positive environment for better communication between/among the instructor and the students. Thus, it should be clear that reading and writing cannot be separated, nor the other skills. Language skills, both receptive and productive, should be integrated. In this sense, the best medium to link human language and creativity is literature. It is an act of imagination and creation. Literary texts are regarded as tools where readers communicate with the text's meaning. In times, it can evoke and provoke readers especially when readers interact with the events, in fiction, scenes, in plays, and speakers, in poetry. The core of a literary text is imaginative and creative quality that inspires learners to respond both intellectually and emotionally when reading or responding to a text. Using literature in English language classrooms leads to creativity and open-ended dialogues between the learners and the language instructor, and activates critical thinking skills among the students. In short, literature touches the learners' emotions and stimulates their intellect to go beyond the literal meaning of language.
\end{abstract}

Keywords: Critical thinking, Language Skills, Literature, Teaching and Learning, Writing Skills

\section{Introduction}

In the last ten years, there is an immense research conducted on the use of literature in English language teaching classrooms. This is due to the positive effects of literary texts on second language learners. The impact of these effects can be perceived in two ways, specifically. Literary genres engage and motivate language learners better via their provocation and evocation. In addition to these, literary texts are the best tools for language learners, all levels, to read and learn the language constructions and structures in use. In this vein, literature is creative and imaginative writing. Utilizing literature, it can be either national or world literature, in teaching and 
learning English language opens unlimited opportunities, in terms of activities in teaching and learning for both language instructors and learners. The word literature is an umbrella term that includes different genres including: novel, drama, and poetry. And these literary genres are written either in prose or poetry. In English language classrooms, English instructors depend on literary works as essential/additional materials in order to give a different taste to the processes of teaching and learning. Thus, literature can be used in teaching and learning the four language skills: listening, speaking, reading, and writing. These are also regarded as receptive and productive skills, receptive skills include listening and reading, and productive skills include speaking and writing. This literature review paper explores the usage of literature in teaching and learning writing skills. Language and literature and literature and language should be treated as two different sides of the same coin. For language learners, literature includes the culture of the target language, and language is the medium that transcribes its culture through the words. Therefore, language learners should not deal with one side of the coin and ignore the other. In short, language learning should be contextualized, learned in its socio-cultural context.

The significance of this study is to delve into the findings of previous researchers and find out the validity of their application so as to enrich language pedagogy. Arguably, language cannot be grasped through the linguistic texts on language alone. There should be a field where learners will have a chance to use the faculty of imagination and their creative power embedded in each individual to express their psychological and socio-political reality, including values, norms, customs, beliefs, ethical concerns, pains and joys. Above all, language is a means of communication. Since the dawn of civilization, people have tried to write the psychology or sociology of their cultural identity in either prose or poetry. Importantly, the reason is that literary language is more appealing. And it also touches the heart thanks to its vivid memorable and pleasurable essence. Literature is recognized by its aesthetic quality, beauty of language use. Language instructors work eagerly to engage learners in experiences where they are involved emotionally and mentally so that they participate in the process of meaning-making. Of course, different readers have different psychological experience and social backgrounds. In the light of this interpretation, when a language learner reads a literary text, it stirs their personal knowledge to communicate physically, via the five senses, and psychologically, via internal reactions: positively or negatively, with the events, in fiction, scenes, in drama, and speakers, in poems. Literary texts provoke and evoke their readers. For example, for one question that a literary work raises, different learners will have different answers based on their knowledge and experience. Thus, language learners respond differently to a selected literary text.

\section{Research Questions}

This paper discusses the advantages of using literature in teaching and learning writing skills. The whole project is based on two questions that are: 
1) What are the benefits of using literature in teaching writing skills?

2) What are the benefits of using literature in learning writing skills?

\section{Methodology}

In analyzing the current literature on the usage of literature in writing classrooms, the descriptive qualitative design is used to find out the benefits of utilizing literature in teaching and learning writing skills. For that reason, the samples were selected purposefully. The researcher collected data from secondary sources including research articles written between 2015-2021. In interpreting the collected data, the researcher used thematic analysis to demonstrate how the previous scholars tackle using literature in writing classes.

\section{Teaching and Learning Writing Skills through Literature}

When it comes to the skills of any language, the receptive and productive skills should be taken into account. Indeed, the two skills should be integrated not separated. On the one hand, receptive skills mean listening and reading. On the other hand, productive skills include speaking and writing. The title of this section is teaching and learning writing via literature. So, why should we mention these skills of language? What is the connection and interconnection between the two? In fact, good readers are good writers, and vice versa. For second language learners, the best field to read, of course, is literary works. According to Ajoke and Shapii (2017) "literature is language in use" (p. 53). One question to ask again is: what is language? Language includes the four skills: reading, writing, listening and speaking. These skills are used in different forms of communication. In certain places, English language learners have the difficulty of integrating the four skills together, this is true especially in terms of improving them in parallel. Some learners just focus on reading, some just on listening, and others either on listening and speaking. But this is not a proper way how a second language is acquired. In this respect, the purpose behind using literature in English classrooms is to integrate these skills so that students participate in classroom activities and discussions. In fact, literature motivates language learners to use both receptive and productive skills of the target language. Ajoke and Shapii (2017) inserted that "literature encourages students to acquire the four language skills" (p. 54).

Literature should be used in teaching and learning writing skills. Choudhary (2016) stated that an evocative answer is the key characteristic of literature and language instruction and learning. This evocation comes from two factors. First, literary works are imaginative and creative writings fueled by/with human inspiration. Novelists, poets, and dramatists write about the human experience and condition, as literature is the transcription of human condition into words. Second, these texts require their readers to participate in the process of meaning-making. This participation depends on the readers' emotions and thoughts. Once they are engaged and involved in the meaning of the text, they see the characters' conditions and conflicts through their points of view. In this scenario, readers either empathize or sympathize with the 
characters' problems and difficulties. In this regard, readers respond differently to texts based on the essence of the literary genre, whether it's tragic or comic. Thus, literary texts evoke learners as if they are present there, in the fictional world of the characters. As language instructors, literature should be integrated in the activities inside and outside classroom to engage the learners effectively. When learners learn the taste of literary masterpieces, they will seek more, and become independent learners. Mahmud (2017) claimed that "the authenticity of the literary work, the richness of the language, the scope of imagination and creativity and the process of critical thinking, are just a few advantages for using literary genres in the language classroom." Based on what Mahmud stated above, literary texts are authentic materials that means they are reliable, as they are composed by fluent native speakers. As for language learners, it is more preferable to learn and acquire the language constructions and rules in context, that means learn them unconsciously through reading or listening. Writers use language differently so there is a variety of language uses and forms. Writers use language in a creative, imaginative and critical way. Thus, language in literature is vivid, alive, evocative, and provocative. Due to the above-mentioned reasons, literature is the best option to be included in writing classes. Reading a piece of literature enrich the learner's knowledge, and they will respond to the text's meaning based on their understanding of the events, scenes, and emotions, of the speaker.

\section{Vocabulary}

Literature helps learners to learn the meaning of the words in context. Writing instructors can utilize literature for both teaching and learning new words. Ismail and Mallemari (2020) inserted that "when learners read literature, they fling into it. They dive deeper to learn the meaning of the lexical items of the text. This can lead to beneficial effects in learning the language. As such, literature becomes a source of grammar and linguistic rules" (p.274). Knowing the meaning of words and learning how to use them in sentences are the best techniques for improving reading comprehension. Without reading comprehension, learners will not be able to improve their writing. As stated earlier, reading and writing are inseparable acts. It is the instructor's duty to explain this to language learners that writing effectively depends on effective reading. In literary texts, learners should be acquainted with denotation and connotation, language goes beyond the surface meaning in literary texts. In fact, this should be explained in terms of symbols, images, imagery, and figures of speech.

Language instructors should explain denotation and connotation for the learners. On the one hand, denotation is the literal or dictionary meaning of the words. On the other hand, connotation is the emotive meaning that includes implications, associations, and suggestions that words give once they are taken out of the text and placed in their historical, socio-cultural, and political contexts. As Choudhary (2016) mentioned that words have both surface and emotional meanings. Literary works make these associations easier for their readers. For example, when a learner reads a poem or short story, and sees the word flower, they will think about both the textual and 
contextual meanings of the word 'flower.' The literal meaning is easy to grasp, but for the connotations it may mean spring, beauty, goodness, fragile, and a lady based on the contextual clues given in the text. Learners should find textual evidence within the work then decide on the specific meaning of the selected word.

Teaching vocabulary is a good strategy for second language learners because of two reasons. First, learning new words help learners to enhance their reading comprehension. Second, it also helps them to write better without stopping. When a learner writes a sentence, paragraph or essay, they will need words. Thus, the first approach for effective writing is to have a plethora of words. Learners should learn the meanings of these words, and the use of these words in sentences. If learners do not know enough words, they cannot read well. Once they cannot read well, they will not be able to write well.

\section{Grammar}

For elementary and intermediate language learners, grammar should be acquired unconsciously. By that, learners learn grammatical structures and constructions through their exposure to the target language. As we all know, grammar is the essence of writing. Without correct grammar, writing will be meaningless. In this scenario, communication will not take place. As a result, there will be misunderstanding, chaos, and disorder. As for English language learners, literary texts can be utilized for both teaching and learning grammar. Sajeevlal (2017) inserted that "also, short story can be used as a valuable tool for improving the sub-skills of writing, i.e., vocabulary development, development of ideas, grammar and the logical and critical thinking" (p. 461). Short stories should be utilized to develop the sub-skills of writing of the learners.

When reading a literary text, learners will acquire the grammatical structures, constructions, unity, and coherence unconsciously. Sometimes learners will imitate the writing style of a writer as a model for their own writing. Leal (2015) explained that the structure, grammar, structure, and vocabulary of a literary text could be seen by learners as a model for writing. This claim is also supported by the findings of another study conducted by Şen Bartan (2017). Based on the experimental study that he conducted, in the post-test the language, content, organization, and communication level were developed. The findings of the study supported the idea that there is a strong relationship between reading and writing skills.

In learning and teaching writing skills, grammar should be taught either consciously or unconsciously. Teaching grammar unconsciously is going to work better for the language learners because it will help them to focus on other techniques of writing not just grammatical rules. As for learning, the same is true. Learning syntactical rules and constructions should be unconscious. This should be acquired through internalized reading. In this sense, internalization implies the unconscious acquisition of linguistic structures and rules. 


\section{Personal and Cultural Awareness}

Another characteristic of using literature in teaching and learning writing skills is the development of personal and cultural awareness. Ajoke and Shapii (2017) inserted that the position of literature is "to expose learners to different valuable experiences, real and imaginative, building in students the love for extensive and sustained pleasurable reading" (p.53). Based on that, a learner should get the idea that literature has many advantages depending on both individual and collective realizations. There are literary texts, but it is due to readers that a text gets a specific meaning. In other words, if there are no readers, there are no texts. When a learner responds to a text, they use their own language, words and grammar, to express their internal feelings and thoughts about the text. In literary texts, there are two levels of language. On the one hand, there is referential language that means words in a literary work have just one meaning. In another word, they just have one single meaning. On the other hand, there is also representational language, in many texts. This is when a word in a text represents something else. According to Choudhary (2016), representational language "involves the use of imagination and enhances their empathy for others and makes the learners more creative" (p.2). Through representational language, learners will have an opportunity to make associations, implications, and suggestions. Thus, they will read the text beyond the surface meaning of the words. Simply, they will think about connotations or contextual implications. Through connotations, learners will learn how to connect the text to its context. This, in essence, makes readers to be critical learners. Later, they will think try to read literary theories and apply them on the texts.

Literary texts help learners to understand the culture of its writers. One benefit of using literature in learning and teaching writing is that it supplies the learner with "cultural information about the country whose language they are learning" (ViolettaIrene, p. 75). So, what is so interesting about using literature in language classes is the idea of linking language and culture through using literature. One cannot use language properly if they do not have enough information about the culture that it belongs to. Language represents the cultural norms, values, customs, and traditions. Thus, literature is a platform to learn both the language and the culture. Bilal et al. (2013) mentioned that "culture teaches students to understand and respect people's differences" (p.30). This means that knowing about other cultures makes them learners to be open-minded. And this leads to emotional and social development of the character. According to Rozak et al. (2018) the language teacher has to begin to "build awareness that literature can develop character, honing ethics, manners, acquisition of language and others. Language learning should begin with a literary work" (p.137). Finally, using literature in writing classes activates the critical thinking skills among the learners based on the findings of Adam (2015). And indeed, critical thinking skills are the most important skills in the $21^{\text {st }}$ century. Therefore, instructors should utilize literature in their writing classes because it provides learners with the basic skills of their time, and transforms them to be creative in their professional future careers. 


\section{Writing Activity inside the Class}

Instructors can arrange different activities, based on their selected assessment tools, inside the class. These should be based on the level, age, and interest of the learners. Remember that all of this is to create a positive environment for the learners to experience a better sense of learning and being a learner. Violetta-Irene (2015) clarified the idea that the activities inside the class should be based on needs analysis. That means, simply, based on the needs the activities inside the class will change. This makes using literature more vivid because there is this sense of being dynamic and flexible while using it inside the classroom and outside university. For example, an instructor sees that their students need improvement in grammar, so they can arrange an activity based on that need. Or another one might see that the learners have problem with unity and coherence, so another type of activity should be organized. Of course, for each type of activity inside the class, different texts are required. It is better for the psychology of the learners to have different texts, genres, for different activities. Or if we are dealing with individual learners, they should be given the freedom to select a text based on their own interest and level.

Violetta-Irene (2015) proposes three stages while using literature in the class. These stages are: pre-reading, while reading, and post-reading. And reading can be changed to the other skills. For each stage, enough guides should be given to the learners. In communicative classrooms where they use student-centered learning, this will be effective because the instructor can divide the learners into small groups and ask them to collaborate and cooperate with each other. In each stage, learners should be asked about the meaning of words, and the reasons behind their selection. In this way, they will be aware about the reasons behind their selections. For more information on the class activities, instructors can consult Gillian Lazar's Literature and Language Teaching (1993). This is a great source with lots of activities and tasks. Further, Bilal et al. (2013) said that English language instructors can create different activities so as to help the students develop their writing skills. These skills include writing dialogues, paraphrasing sentences, summarizing a text, writing about the theme of a text, writing a paragraph about a theme or why a character did that specific thing. Indeed, all of these will be answered after the learner has understood the text very well, this is after reading and understanding. After reading and understanding, the learners can produce something out of their understanding of the text. For the instructors, it is better to depend on reader response because students will respond differently to the same story. This is based on their knowledge and experience.

\section{The Benefits of Using Literature in Teaching and Learning Writing Skills}

Using literature in writing classes has many benefits. These advantages can be summarized as follows:

- Literature motivates and engages learners.

- Literary texts enrich the input language of the students. 
- Literary texts are authentic materials

- They expand the learner's imagination

- They develop their emotional and social skills as they interact with the meaning of the text

- Literary texts show the power of creativity of language in use

- They unconsciously show the learners how words are used in context

- They move the learners' sympathy and empathy

- They inform learners what it means to be a human being

- Literature shows human experience and condition

- In terms of language development, they show learners grammatical structures, constructions, punctuation, style, unity, coherence, parallel structure, figurative language in contextual usage

- Learners acquire these language structures unconsciously

- If a learner is touched by a text, then they can easily write about that experience because it is both memorable and pleasurable

- Literature and language are the two sides of the same coin

- Learners should start learning the target language with literature

- Literature raises the learners' cultural awareness

- The most important characteristic is that through literature instructors create a chance for their learners to integrate the four skills while the learners do not realize this purpose

- Learners learn a lot of new words and their meaning with their use in sentences

- Above all, learners grow emotionally and intellectually as they communicate with literary characters.

\section{Future Research}

Using literature in English language classes is a new trend in language and literature research, and further studies can be conducted on using literature in language teaching. Further research is needed to establish it as a method of teaching, the method of using literature in language teaching or literature-based language teaching. Based on the findings of this study, the researcher suggests these topics for the future researchers:

- The use of literature in developing $21^{\text {st }}$ century skills

- Using literature in teaching and learning syntax

- Teaching and learning vocabulary through literature

- The use of literature in teaching and learning critical thinking skills

- Teaching and learning reading through literature

- Using literature in teaching and learning speaking skills

- The use of literature in teaching and learning emotional and social skills

- The integration of short stories into reading/ writing assessment tools

- Using drama techniques in teaching English language

- Using literature in teaching and learning cultural consciousness

- The techniques of using literature in language teaching 
- Teaching methods in literature-based language teaching

- The selection of literary texts, or genres, in literature-based language teaching

- Using Bloom's Taxonomy in teaching literature-based language teaching

- Teaching and learning figurative language through literature

\section{Recommendations for English Language Departments}

Finally, the researcher comes to the realization that literature should be taught at all levels, from kindergarten to higher education. It should be stated that some English language teachers may not be able to use literature in their classes, or they may not know about the importance of literature in language teaching. So, the researcher recommends different training courses for all levels based on getting the most and best from integrating literature into the language curriculum. One point that should be mentioned here is that the selection of the texts must depend on the students' needs. ELT departments should have an aisle, in their libraries that include numerous short stories for different levels. English language instructors should respect the interest and level of their students when assigning a literary text. Different guides and explanations are needed when assigning different literary genres. All of these should be taken into consideration when using literature in English language teaching.

\section{Conclusion}

Through literature, learners can culminate the four language skills together. Literature is a field where we see the language in real operation both in terms of form and content. Literary works are real materials from native speakers. Therefore, novice learners expose themselves to authentic materials like the masterpieces of literature or the classics. Literature shows the power of writing and the ability of reading and understanding. Thus, when writing instructors use literature, it makes their classes more active, engaging, motivating, and effective. As a result, the learning process for the language learners becomes more stimulating, engaging, and practical. Finally, literature is the best medium for writing instructors to help their learners internalize reading, and externalize that through writing. So, literature should be integrated into language teaching classes especially writing classes.

\section{References}

Adam, A. A. S. (2015). Developing EFL learner's narrative writing through using short stories - The case of Al-Baha University students. European Journal of Language and Literature Studies, 3 (4), 1-8. Retrieved on 15 December, 2021 from https://www.eajournals.org/wp-content/uploads/Developing-EFLLearners-Narrative-Writing-Through-Using-Short-Stories-The-Case-of-AlBaha-Universiy-Students.pdf

Ajoke, A., \& Shapii, A. (2017). Problem and prospect of using literature to teach writing in English as a second language. International Journal of Humanities and Social Science Invention, 6(2), 53-57. 
Bilal H., Tariq, A., Masood, A., Nasim, G., \& Iqbal, A. (2013). Developing second language reading comprehension through short story. Journal of Literature, Languages and Linguistics, 1. 26-31.

Choudhary, S. (2016). A literary approach to teaching English language in a multicultural class - room. Higher Learning Research Communications, 6(4). DOI: 10.18870/hlrc.v6i4.352.

Ismail, I., \& Mallemari, M. (2020). Teaching writing skill through English Literature: Palestine as an example. International Journal of Science and Research, 9, 274-278. 10.21275/SR20828165839.

Lazar, G. (1993). Literature and language teaching: A guide for teachers and trainers. Cambridge, England: Cambridge University Press.

Leal, P. (2015). Connecting reading and writing using children's literature in the university 12 classroom. Reading in a Foreign Language. 27 (2), 199-218. Retrieved on 10 September from https://files.eric.ed.gov/fulltext/EJ1078427.pdf

Mahmud, M. (2017). Teaching students to develop paragraphs by poetry writing. International Journal of Language Education. 1 (1), 37-50. DOI:10.26858/ijole.v1i1.2870

Rozak, R., Mulyati, Y., Damaianti, V., Sumiyadi, S. (2018). Developing reading skills and beginning writing through literary literacy, 263. 135-141. DOI:10.2991/iclle-18.2018.21

Sajeevlal, U. (2017). Teaching writing skills using short stories. Int. J. Adv. Res. 5(2), 461-464.

Şen Bartan, Ö. (2017). The effects of reading short stories in improving foreign language writing skills. The Reading Matrix, 17 (1). 59-74. Retrieved on 18 August, 2021 from https://www.researchgate.net/publication/315714627_The_Effects_of_Reading _Short_Stories_in_Improving_Foreign_Language_Writing_Skills

Udhya, S. (2017). Teaching writing skills using short stories. Int. J. of Adv. Res, 5 (2), 461-464. DOI:10.21474/IJAR01/3171

Violetta-Irene, K. (2015). The use of literature in the language classroom: Methods and aims. International Journal of Information and Education Technology, 5. 74-79. DOI: 10.7763/IJIET.2015.V5.479. 